\title{
Honduras ante la Corte Interamericana de Derechos Humanos: Jurisdicción Contenciosa y Consultiva
}

Honduras before the Inter-American Court of Human Rigths: Litigation and Advisory Jurisdiction

\author{
Abog. Jimena Bonilla Cabañas*
}

\section{Resumen}

El presente artículo describe y analiza la jurisdicción contenciosa y consultiva de Honduras ante la Corte Interamericana de Derechos Humanos, dando a conocer en primer lugar, los antecedentes históricos de Honduras ante este Tribunal Internacional, en un periodo comprendido desde el año 1982-2015, analizando los diferentes derechos humanos violentados, en el cual se declara la responsabilidad internacional del Estado.

Así mismo se presentan datos importantes en relación a las diferentes medidas de reparación ordenadas al Estado de Honduras, las que consisten en diversas medidas como ser: la de indemnización, satisfacción y garantías de no repetición. Posteriormente se describe, la etapa de supervisión de cumplimiento de las sentencias, en el que se realiza un análisis breve de la situación actual del número de sentencias que aún están pendientes de ser cumplidas.

Finalmente se resalta la importancia del Control de Convencionalidad, en la aplicación de las normas internacionales de derechos humanos, de parte de un Poder judicial competente, independiente e imparcial.

Palabras Clave: Jurisdicción Contenciosa, Responsabilidad Internacional, Derechos Violentados, Medidas de reparación, control de convencionalidad.

\section{Abstract}

This article describes and analyzes the contentious and advisory jurisdiction of Honduras before the Inter-American Court of Human Rights, presenting first, the historical background of Honduras before the International Tribunal, in a period since 1982-2015, analyzing different human rights violated, in which the State's international responsibility is declared.

Also important data are presented in relation to the various measures of reparation ordered the State of Honduras, which consist of various measures such as: the Compensation, satisfaction and guarantees of non-repetition. Described later, the stage of monitoring compliance with the judgments, in which a brief analysis of the current situation of the number of statements that are yet to be fulfilled is performed.

Finally the importance of conventionality control in the application of international human rights, a competent, independent and impartial judiciary is highlighted.

Key Words: Contentious Jurisdiction, International Responsibility, violated rights, reparation measures, control of conventionality.

Fecha de Recepción: miércoles 16 de marzo 2016

Fecha de Aprobación: viernes 20 de octubre 2016

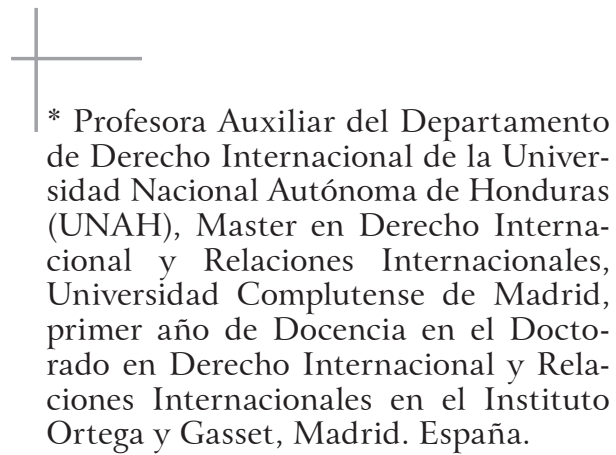

Ortega y Gasset, Madrid. España. 


\section{Introducción}

El rol del estado de Honduras, ante la jurisdicción contenciosa de la Corte Interamericana de Derechos Humanos, en un transcurso de 33 años, ha sido muy activa y el Tribunal ha sido determinante en establecer reiteradamente, la obligación del Estado de proteger y garantizar los derechos de todos/ as sus ciudadanos. En contrario sensu a la jurisdicción consultiva, en la que el Estado de Honduras hasta la fecha no ha solicitado ninguna opinión consultiva ante este importante órgano jurisdiccional. En el periodo comprendido del año 1982 -2015, esta Corte ha conocido 10 casos contenciosos, en los cuales el Estado ha sido condenado en 9, por violación al derecho a la vida, a la integridad personal, a la libertad personal, libertad de asociación y expresión, todos los cuales son derechos reconocidos en la Convención Americana de los Derechos Humanos, firmada y ratificada por el estado hondureño.

A la fecha existen dos casos pendientes de resolución por este Tribunal, en relación al reconocimiento a los territorios ancestrales, como es el caso de la Comunidad Garífuna de Punta Piedra y la Comunidad Garífuna de Triunfo de la Cruz.

A través de las diferentes resoluciones de este órgano jurisdiccional internacional, se han establecido medidas de reparación para el Estado, que han consistido en medidas de indemnización como ser: reparación del daño material e inmaterial, daño emergente y lucro cesante. Medidas de satisfacción; monumentos, placas, honor a las víctimas, publicación de las sentencias, perdón público, reintegro a cargos públicos, cátedras universitarias en temas de Derechos Humanos. Garantías de no repetición; obligación de investigar, identificar, juzgar y sancionar, medidas educativas destinadas a los órganos del Estado.

Así mismo a través del presente trabajo se destaca la importancia del control de convencionalidad del estado hondureño, el cual al haber firmado y ratificado diversos tratados internacionales en materia de derechos humanos, se obliga a respetar y garantizar los derechos reconocidos en ellos, y a adoptar las medidas necesarias para que estos derechos sean efectivos, respetados y garantizados.

\section{Metodologia}

El artículo de investigación desde la perspectiva de los derechos humanos proporciona un amplio estudio jurídico donde la doctrina, las leyes y la jurisprudencia se consolidan a fin de examinar las diversas resoluciones emitidas por un organismo Internacional tan relevante como lo es, la Corte Interamericana de Derechos Humanos.

Se desarrolló entonces, una investigación de tipo analítica, descriptiva y documental, ya que se buscó profundizar en aquellos razonamientos contenciosos evidenciados en los casos más emblemáticos donde Honduras ha tenido un impacto universal y ha sido utilizada como referente jurídico tanto por tribunales internacionales, como para contribuciones fundamentales en el estudio y desarrollo del derecho internacional.

\section{Antecedentes de Honduras ante la Corte In- teramericana de Derechos Humanos.}

El estado de Honduras ratificó la Convención Americana de Derechos Humanos, el 5 de septiembre de 1977 y presentó ante la Secretaría General de la Organización de Estados Americanos, el instrumento de reconocimiento de la competencia de la Corte Interamericana de Derechos Humanos, el 09 de septiembre de 1981.

El primer caso en la jurisdicción contenciosa de la Corte Interamericana de Derechos Humanos, fue el caso Velásquez Rodríguez $z^{1}$ en el año 1982, y cuya sentencia es un precedente jurisprudencial en materia de desapariciones forzosas para todos los Estados miembros de la Organización de Estados Americanos.

Posteriormente la Corte Interamericana de Derechos Humanos, analizó en el periodo de 1982 a 2003, tres casos más de desaparición forzada; Saúl Godínez Cruz², Francisco Fairen Garbi y Yolanda Solís Corrales ${ }^{3}$ y Juan Humberto Sánchez ${ }^{4}$. En el cual el modus operandi de todos, seguía el mismo patrón: a) vigilancia de una persona determinada; b) uso de vehículos especiales en el secuestro; c) los secuestros eran selectivos; d) las víctimas eran llevadas a cárceles clandestinas; e) las víctimas eran torturadas y sometidas a tratos crueles e inhumanos; d) finalmente eran sepultados en cementerios clandestinos.

A partir de estos casos, la Corte Interamericana de Derechos Humanos ha desarrollado Jurisprudencia en relación a las obligaciones que el Estado de Honduras ha asumido al firmar y ratificar la Convención Americana sobre Derechos Humanos.

1- Velásquez Rodríguez, fue un estudiante universitario, capturado el 12 de septiembre de 1981 en la ciudad de Tegucigalpa, posteriormente torturado y asesinado por agentes del Estado, dentro del contexto de la implementación de la Doctrina de Seguridad Nacional, cuyo objetivo fue erradicar a quienes estaban en contra de la ideología predominante en esa época.

2- Saúl Godínez Cruz, era un dirigente magisterial, que había participado en varias huelgas. Fue capturado por militares y civiles, cuando se conducía en su motocicleta en el trayecto de la ciudad de Choluteca a Tegucigalpa.

3- Fairen Garbi y Yolanda Corrales, de origen costarricense, quienes entraron a territorio hondureño el 11 de diciembre de 1981 y en la cual el Estado de Honduras fue declarado exento de responsabilidad internacional.

4- Caso conocido por la Corte Interamericana de Derechos Humanos, 15 años después de las primeras sentencias de desaparición forzada. Juan Humberto Sánchez trabajaba como Técnico Operador de la Radio Venceremos del Frente Farabundo Martí para la Liberación Nacional de El Salvador. 
Entre los años 2006 al 2013, la Corte Interamericana ha dictado sentencias importantes referentes a la violación al derecho a la libertad, derecho a la vida e integridad personal, derecho a la libertad de expresión y asociación. En relación al derecho a libertad, la Corte dicto sentencia en el caso Alfredo López Álvarez ${ }^{5}$, quien estuvo en prisión preventiva durante seis años y cuatro meses, detenido junto a los condenados y prohibiéndosele el derecho a hablar en su idioma materno. En relación al derecho a la vida e integridad personal, tenemos una sentencia transcendental en relación a los niños en situación de riesgo social, y es el caso Servellón García y otros ${ }^{6}$, en el cual la Corte Interamericana reconoció el contexto de violencia en contra de los niños y jóvenes en Honduras, caracterizada

5- Alfredo López Alvarez, líder garífuna, Presidente del Comité de Defensa de tierras Triunfeñas (CODETT) y Vicepresidente de la Organización Fraternal Negra de Honduras (OFRANEH).

6- Caso Servellón García, involucra a cuatro jóvenes, que fueron detenidas en un operativo policial, en el marco de la respuesta estatal de represión preventiva armada a las pandillas juveniles. por las ejecuciones extrajudiciales y la impunidad en que se mantienen los hechos. Así mismo la sentencia en el caso de Pacheco Teruel y otros ${ }^{7}$; la Corte Interamericana manifiesta la gravísima situación de las cárceles en nuestra región americana, existiendo una emergencia humanitaria, por las deficiencias estructurales que presentan estos centros.

Y en los casos de Blanca Jeannette Kawas y Carlos Luna; la Corte reconoce los actos de agresión, amenazas y ejecuciones que son víctimas los defensores del medio ambiente en Honduras, debiéndose implementar una política integral de protección a defensores y defensoras de derechos humanos.

En el año 2015, se establece una Jurisprudencia muy importante para Honduras y los países miembros de la Organiza-

7- Caso Pacheco Teruel y Otros; hace referencia al incendio en la celda No.19 del Centro Penal de San Pedro Sula, ocurrido el 17 de Mayo de 2004, en el cual perdieron la vida 107 internos.

\section{Actividad de la Corte Interamericana sobre Honduras (1982-2015)}

\begin{tabular}{|l|r|l|}
\hline \multicolumn{1}{|c|}{ Desiciones } & Cantidad & \multicolumn{1}{|c|}{ Derechos/temas recurrentes } \\
\hline Contenciosos & 10 & $\begin{array}{l}\text { Derecho a la vida (ejecuciones extrajudiciales), integridad (desapariciones forzo- } \\
\text { sas y torturas), libertad (detención arbitraria), libertad de asociación y libertad de } \\
\text { expresión. }\end{array}$ \\
\hline Excepciones priliminares & 6 & Agotamiento del recurso interno \\
\hline Fondo y reparaciones & 6 & Arts. 1.1, 4, 5, 7, 8 y 25 de la Convención \\
\hline Casos pendientes & $2^{9}$ & Reconocimiento a los territorios ancestrales \\
\hline Opiniones consultivas & 0 & \\
\hline Medidas provisionales & 8 & Garantizar la vida, integridad personal y libertad de expresión. \\
\hline Desestimadas & $2^{10}$ & \\
\hline - Resoluciones & 18 & \\
\hline Supervisión del Cumplimiento & 6 & Consignación de indemnización de los familiares de las víctimas, publicación de la \\
& 6 & \\
\hline - Casos resolutiva de la sentencia, iniciar los procesos penales contra los culpables.
\end{tabular}

ción de Estados Americanos, en materia de derechos políticos, libertad de expresión y asociación, y es el caso López Lone y otros $^{8}$, en la cual la Corte Interamericana, establece la independencia del Poder Judicial y el respeto a la libertad de expresión y asociación de sus Jueces y Magistradas.

Por lo tanto la Jurisprudencia establecida por la Corte Interamericana de Derechos Humanos en los primeros casos de Honduras, ha tenido un impacto mundial y ha sido utilizada tanto por tribunales internacionales, como para contribuciones fundamentales en el estudio y desarrollo del derecho internacional. Los posteriores casos son precedentes fundamentales para determinar las obligaciones que tiene el Estado en relación con la eliminación de prácticas violatorias de derechos humanos.

8- Corte IDH. Caso Lopez Lone y otros. Fondo. Sentencia de 05 de Octubre de 2015.

9- Caso Juan Humberto Sánchez Vs. Honduras. 29 de Mayo de 2013; Caso López Álvarez Vs. Honduras 22 de Noviembre de 2011; Caso Servellón García y otros Vs. Honduras 22 de Noviembre de 2011; Caso Kawas Fernández Vs. Honduras 23 de Octubre de 2012; Caso Pacheco Teruel y otros Vs. 


\section{Derechos Humanos Violentados}

En el caso de Honduras, la Corte Interamericana ha declarado violentado en todos los casos que han sido sometidos a su conocimiento, el derecho a la integridad personal contenido en el artículo 5 de la Convención Americana sobre Derechos Humanos.

En la primera sentencia ${ }^{10}$ en el ejercicio de la jurisdicción contenciosa, la Corte declaro la violación al derecho a la integridad personal por dos razones: solo el hecho de aislamiento prolongado y de la incomunicación coactiva, representa un tratamiento cruel e inhumano que lesiona la integridad psíquica y moral de la persona y el derecho de todo detenido a un trato respetuoso de su dignidad humana.

En el caso de Juan Humberto Sánchez ${ }^{11}$, la Corte estableció que ser víctima de una detención ilegal, independientemente de la duración de la misma, produce una violación del derecho a la integridad personal y reitera su jurisprudencia sobre la presunción de que solo el hecho de estar incomunicado constituye un trato inhumano, degradante y agresivo.

En cuanto a la obligación que tienen los Estados de garantizar los derechos de los detenidos y, ofrecer a estos las condiciones compatibles con la dignidad, la Corte Interamericana retoma la jurisprudencia de la Corte Europea señalando que "el Estado debe asegurar que una persona este detenida en condiciones de que sean compatibles con el respeto a su dignidad humana, que la manera y el método de ejercer la medida, no lo someta a angustia o dificultad que exceda el nivel inevitable de sufrimiento intrínseco a la detención ${ }^{12}$.

Así mismo la Corte Interamericana reitera a través de la sentencia emitida en el caso Servellón García y otros ${ }^{13}$, que cuando el derecho a la libertad personal es vulnerado, se genera un riesgo de que se produzca la vulneración de otros derechos, como la integridad personal y, en algunos casos, la vida.

En el caso Kawas Fernández ${ }^{14}$, se sienta un importante pre-

Honduras 27 de Abril de 2012; Caso Luna López Vs. Honduras 27 de Enero de 2015; Caso López Lone y otros Vs. Honduras 5 de Octubre de 2015

10- Corte IDH. Caso Velásquez Rodríguez Vs. Honduras. Fondo. Sentencia de 29 de julio de 1988.

11- Corte IDH. Caso Juan Humberto Sánchez Vs. Honduras. Fondo. Sentencia 07 de Junio de 2003.

12- Corte IDH. Caso López Álvarez. Fondo. Sentencia 01 de Febrero de 2006

13- Corte IDH. Caso Servellón García y otros Vs. Honduras. Fondo, Reparaciones y Costas. Sentencia 21 de septiembre de 2006. Párr.79.5 y siguientes.

14- Corte IDH. Caso Kawas Fernández Vs. Honduras. Fondo, Reparaciones y Costas. Sentencia 03 de Abril de 2009. Párr. 50. cedente, ya que la Corte declara que se puede declarar la violación del derecho a la integridad psíquica y moral de familiares directos de víctimas de ciertas violaciones de madres y padres, hijos e hijas, esposos y esposas, compañeros y compañeras permanentes, siempre que ello responda a las circunstancias particulares en el caso.

Finalmente en el caso Pacheco Terue ${ }^{15}$, la Corte retoma el reconocimiento de responsabilidad internacional hecho por las autoridades estatales, incluyendo la violación del derecho a la integridad, al declarar las violación al artículo 5.6. de la Convención, al no permitir a los internos realizar actividades productivas, por considerarlos miembros de maras. La violación al artículo 5.4. de la Convención, en perjuicio de 22 internos que se encontraban en prisión preventiva por el delito de asociación ilícita, quienes compartían la misma celda con los internos condenados. Adicionalmente el Estado violento el artículo 5.1. de la Convención en perjuicio del grupo de 83 familiares individualizados, en razón de los sufrimientos inherentes al maltrato a los fallecidos durante el incendio.

En cuanto a la violación a la libertad de asociación, me remito a las sentencias emitidas por la Corte Interamericana en los casos Kawas Fernández ${ }^{16}$ y Carlos Luna, en la cual la Corte declara que de la "Libertad de Asociación se derivan obligaciones positivas de prevenir los atentados contra la misma, proteger a quienes la ejercen e investigar las violaciones de dicha libertad". Estas obligaciones positivas deben adoptarse, incluso en la esfera de relaciones entre particulares, si el caso así lo amerita. Citando los casos Huilca Tecse Vs Perú y Cantoral Huamaní y García Santa Cruz Vs. Perú, la Corte reconoce que la libertad de asociación solo puede ejercerse en una situación en que se respeten y garanticen plenamente los derechos humanos fundamentales, en particular los relativos a la vida y a la seguridad de las personas.

15- Corte IDH. Caso Pacheco Teruel y otros Vs .Honduras. Fondo, Reparaciones y costas. Sentencia de 27 de abril de 2012, párra.43.

16- Corte IDH. Caso Kawas Fernández Vs. Honduras. Fondo, Reparaciones y Costas. Sentencia 03 de Abril de 2009. Párr. 144. 
Honduras ante la Corte Interamericana de Derechos Humanos: Jurisdicción Contenciosa y Consultiva

a. Casos ante la Corte Interamericana de Derechos Humanos

\begin{tabular}{|c|c|c|c|c|c|c|}
\hline \multirow{2}{*}{ No. } & \multirow{2}{*}{ Caso } & \multirow{2}{*}{ Tema/Victima } & \multicolumn{4}{|c|}{ Fechas por tipo de sentencia } \\
\hline & & & $E P^{19}$ & $F^{20}$ & $R$ y $C^{21}$ & $I S^{22}$ \\
\hline 1 & Velásquez Rodríguez & $\begin{array}{l}\text { Desaparición forzada/Dirigente Es- } \\
\text { tudiantil }\end{array}$ & \multicolumn{2}{|c|}{29 julio 1988} & 21 julio 1989 & $\begin{array}{c}17 \text { agosto } \\
1990\end{array}$ \\
\hline 2 & Godínez Cruz & $\begin{array}{l}\text { Desaparición Forzada/ Docente de } \\
\text { educación secundaria }\end{array}$ & 26 junio 1987 & 20 enero 1989 & 21 julio 1989 & $\begin{array}{c}17 \text { agosto } \\
1990\end{array}$ \\
\hline 3 & $\begin{array}{l}\text { Juan Humberto Sán- } \\
\text { chez }\end{array}$ & $\begin{array}{l}\text { Desaparición Forzada/ Comunica- } \\
\text { dor del FMLN }\end{array}$ & \multicolumn{3}{|c|}{7 junio 2003} & $\begin{array}{c}17 \text { noviembre } \\
2003\end{array}$ \\
\hline 4 & López Álvarez & $\begin{array}{l}\text { Privación de Libertad/Dirigente de } \\
\text { Organización de Derechos Huma- } \\
\text { nos }\end{array}$ & - & \multicolumn{2}{|c|}{1 febrero 2006} & - \\
\hline 5 & $\begin{array}{l}\text { Servellón García y } \\
\text { otros }\end{array}$ & $\begin{array}{l}\text { Violación al derecho a la vida e in- } \\
\text { tegridad personal/ Jóvenes }\end{array}$ & - & \multicolumn{2}{|c|}{21 septiembre 2006} & - \\
\hline 6 & Kawas Fernández & $\begin{array}{l}\text { Violación al derecho a la vida e } \\
\text { integridad personal y libertad de } \\
\text { asociación y expresión/ Defensora } \\
\text { Ambientalista. }\end{array}$ & - & \multicolumn{2}{|c|}{03 abril 2009} & \\
\hline 7 & Pacheco Teruel & $\begin{array}{l}\text { Violación al derecho a la vida e } \\
\text { integridad personal/Privados de } \\
\text { libertad }\end{array}$ & - & \multicolumn{2}{|c|}{27 abril 2012} & - \\
\hline 8 & Luna López & $\begin{array}{l}\text { Violación al derecho a la vida e } \\
\text { integridad personal y libertad de } \\
\text { asociación y expresión/ Defensora } \\
\text { ambientalista. }\end{array}$ & - & \multicolumn{2}{|c|}{10 octubre 2013} & - \\
\hline 9 & López Lone & $\begin{array}{l}\text { Violación a los derechos políticos, } \\
\text { libertad de expresión, libertad de } \\
\text { asociación/ Jueces del Poder Ju- } \\
\text { dicial. }\end{array}$ & & \multicolumn{2}{|l|}{5 octubre 2015} & - \\
\hline
\end{tabular}

En relación a la violación a las garantías judiciales y el derecho a la protección judicial contemplados en los artículos 8.1 y 25.1 de la Convención Americana de Derechos Humanos, el estado de Honduras ha violentado estas garantías en diversos casos, como ser en el caso de Kawas Fernández, López Álvarez y Pacheco Teruel, en el cual se violentó la garantía del Plazo razonable en donde la Corte ha tomado en consideración cuatro aspectos: a. complejidad del asunto b. actividad procesal del interesado. c. conducta de las autoridades judiciales $d$. afectación generada en la situación jurídica de

\footnotetext{
17- EP: Excepciones preliminares;

18- F: fondo

19- $R$ y C: Reparaciones y costa

20- IS: Interpretación de sentencia
}

la persona involucrada en el proceso. Estos parámetros han sido sustento para que en los casos mencionados, el estado de Honduras haya sido condenado.

Y en cuanto al derecho a la defensa se muestra la inobservancia del estado hondureño a esta garantía, en el caso López Álvarez, quién no tuvo la oportunidad de rendir la declaración indagatoria en la presencia de su abogado, con quién tuvo comunicaciones algunos días después de su detención.

Ante estas múltiples violaciones a los derechos consagrados en la Convención Americana de Derechos Humanos, el estado de Honduras debe dar fiel cumplimiento a las medidas de reparación y recomendaciones emanadas de la Corte Interamericana, para evitar incurrir en nuevos casos de responsabilidad internacional. 
Medidas de reparación integral decretadas por la Corte IDH, en los fallos contra Honduras 1987-2015.

\begin{tabular}{|c|c|c|c|c|c|c|c|c|c|}
\hline Medidas de indemnización (pecuniarias) & 1 & 2 & 3 & 4 & 5 & 6 & 7 & 8 & 9 \\
\hline $\begin{array}{l}\text { Indemnización por daño material (daño emergente y } \\
\text { lucro cesante) }\end{array}$ & $\mathrm{X}$ & $X$ & $X$ & $\mathrm{X}$ & $X$ & $X$ & $X$ & $X$ & $x$ \\
\hline Indemnización por daño inmaterial (moral) & & & & $X$ & $x$ & $X$ & $X$ & $X$ & $x$ \\
\hline Costas y gastos & & & $x$ & $\mathrm{x}$ & $x$ & $x$ & $x$ & $x$ & $X$ \\
\hline \multicolumn{10}{|l|}{ Medidas de satisfacción (dignificación) } \\
\hline Reintegro a cargos similares con los mismos beneficios sociales. & & & & & & & & & $\mathrm{X}$ \\
\hline Monumentos, placas y otros símbolos en honor a las víctimas & & & & & $x$ & $X$ & & & \\
\hline $\begin{array}{l}\text { Publicación de la sentencia (Diario oficial, Prensa nacional, radio, } \\
\text { televisión, web institucional, etc.) }\end{array}$ & & & $X$ & $X$ & $X$ & $X$ & $X$ & $X$ & $X$ \\
\hline $\begin{array}{l}\text { Acto protocolario de reconocimiento de la } \\
\text { responsabilidad internacional }\end{array}$ & & & & $X$ & $\mathrm{X}$ & $X$ & $X$ & $X$ & \\
\hline $\begin{array}{l}\text { Cátedras universitarias, diplomados y otras formaciones en derechos } \\
\text { humanos que incluyan un estudio del fallo respectivo y/o de la vida } \\
\text { de la(s) víctima (s). }\end{array}$ & & & & & $\mathrm{X}$ & $X$ & $X$ & & \\
\hline \multicolumn{10}{|l|}{ Garantías de no repetición } \\
\hline Obligación de investigar, identificar, juzgar y sancionar & & & $X$ & & $x$ & $x$ & $\mathrm{X}$ & & \\
\hline $\begin{array}{l}\text { Obligación de protección de las víctimas y sus causahabientes y/o al } \\
\text { grupo social en situación de } \\
\text { vulnerabilidad que ha sido victimizado }\end{array}$ & & & & $X$ & & $X$ & $X$ & & \\
\hline Asistencia médica y psicológica & & & & & & $\mathrm{X}$ & $\mathrm{X}$ & $x$ & \\
\hline $\begin{array}{l}\text { Medidas educativas generales destinadas a los órganos } \\
\text { del Estado en materia de derechos humanos }\end{array}$ & & & & $X$ & $x$ & $X$ & $x$ & $X$ & \\
\hline
\end{tabular}

Tabla 3. Medidas de reparación ordenadas en las sentencias contra la República de Honduras emitidas por la Corte IDH entre 1987-2015. Elaboración propia/ Fuente: sitio oficial Corte IDH: http://www.corteidh.or.cr/

\section{Reparaciones ordenadas al estado de Honduras por la Corte Interamericana de Derechos Humanos.}

La Jurisprudencia de la Corte Interamericana en el tema de reparaciones ha sido amplia y ha evolucionado progresivamente. En el caso de Manfredo Velásquez y Godínez Cruz ${ }^{21}$, se valoró el estado de salud de los familiares de las víctimas, en donde la Corte considero evidente que se produjeron consecuencias psíquicas nocivas, por lo cual las victimas debían ser indemnizadas.

21- Corte IDH. Caso Velásquez Rodríguez Vs. Honduras. Reparaciones y Costas. Sentencia de 21 de julio de 1989, párr.51; Caso Godínez Cruz Vs. Honduras. Reparaciones y Costas. Sentencia de 21 de Julio de 1989,párr..49.
En estos primeros casos que analizó la Corte, si bien se reconoce la indemnización por el daño psicológico sufrido por los familiares de las víctimas, no se otorga ninguna medida de rehabilitación específica.

En los casos posteriores la Corte Interamericana tiene avances significativos en este tema y dispone de la adopción de medidas de rehabilitación, especificando que el tratamiento a otorgarse debe ser dictado por las circunstancias y necesidades particulares de las víctimas, que la medicación y el tratamiento de diagnóstico deben ser incluidos y cubiertos por el Estado, y que el tratamiento psicológico no debe limitarse a la víctima directa de la violación. 
En el caso Jeannette Kawas, la Corte ordenó asistencia psicológica, psiquiatra gratuita para los familiares de las víctimas, así como el suministro de medicamentos que eventualmente requieran y tomar en cuenta los padecimientos de cada uno de los beneficiarios ${ }^{22}$.

En el acuerdo de solución amistosa del caso Pacheco Teruel y otros vs. Honduras, la Corte homologa la medida de rehabilitación en cuanto a la asistencia médica y psicológica para las íctimas ${ }^{23}$.

\section{Cumplimiento de las sentencias de la Corte Interamericana de Derechos Humanos.}

El cumplimiento de las medidas de reparación por parte del Estado de Honduras, ha sido deficiente y actualmente presenta una gran deuda ante la Comunidad internacional. Por ejemplo en el caso de Juan Humberto Sánchez, el Estado dispuso posterior a su exhumación, trasladar los restos a las instalaciones de medicina forense para realizarle pruebas de ADN. Varios años después de la exhumación, el Estado no había entregado los restos a sus familiares, sino que fue hasta en el año 2007, trece años después de la ejecución de la víctima y cuatro años después de la sentencia de la Corte, se hizo formal entrega. Esta demora excesiva en la entrega de los restos, agravo el sufrimiento de sus familiares.

Otro ejemplo es el caso Servellón García y otros, en el cual el acto público de reconocimiento del Estado por su responsabilidad internacional, no cumplió con el objetivo reparador, ya que no incluyo a los familiares de las víctimas en la participación del acto de disculpa, debiéndose realizar otro acto de reconocimiento posteriormente.

Es así como Honduras enfrenta una gran desafío en el cumplimiento de las sentencias dictadas por la Corte Interamericana de Derechos Humanos, al encontrarse actualmente en etapa de supervisión de cumplimiento siete ${ }^{24}$ de las nueves sentencias en las cuales se ha declarado al Estado, responsable por violaciones a los derechos humanos.

\footnotetext{
22- Corte IDH. Caso Kawas Fernández Vs. Honduras. Parr.209

23- Corte IDH. Caso Pacheco Teruel y otros Vs. Honduras. Fondo, Reparaciones y costas. Sentencia de 27 de abril de 2012, párra.115.

24- Caso Juan Humberto Sánchez Vs. Honduras, 29 de Mayo de 2013; Caso López Álvarez Vs. Honduras 22 de Noviembre de 2011; Caso ServeIlón García y otros Vs. Honduras 22 de Noviembre de 2011; Caso Kawas Fernández Vs. Honduras 23 de Octubre de 2012; Caso Pacheco Teruel y otros Vs. Honduras 27 de Abril de 2012; Caso Luna López Vs. Honduras 27 de Enero de 2015; Caso López Lone y otros Vs. Honduras 5 de Octubre de 2015
}

\section{Control de convencionalidad en Honduras.}

El estado de Honduras ha sido parte desde sus inicios, de los procesos de humanización y socialización del derecho internacional, fue uno de los 51 estados miembros fundadores originarios de la Organización de Naciones Unidas y el 21 Estado que participo en la Novena Conferencia Internacional Americana realizada en Bogotá, Colombia, en abril de 1948, en la que se adoptó la Carta de la OEA y la Declaración Americana de los Derechos y deberes del hombre ${ }^{25}$.

Desde entonces Honduras, ha ratificado una serie de instrumentos universales y regionales que reconocen la supremacía de los derechos humanos frente al poder del Estado y cuyas disposiciones generan obligaciones erga omnes, que tiene un carácter multilateral en tanto que todos los Estados están interesados en que se respeten, por lo que pueden exigir su observancia, y en su defecto la responsabilidad internacional del Estado infractor en caso de incumplimiento.

En el ámbito de las Naciones Unidas, Honduras ha ratificado los dos grandes instrumentos generales: el Pacto Internacional de Derechos Civiles y Políticos y el Pacto Internacional de Derechos Económicos, Sociales y Culturales. Así mismo ratifico siete instrumentos específicos entre ellos: la Convención contra la tortura y otros tratos crueles, inhumanos o degradantes, la Convención sobre los Derechos del Niño, la Convención sobre los derechos de las personas con discapacidad, entre otros.

En el ámbito de la OEA, el estado de Honduras ratifico la Convención Americana sobre Derechos Humanos y sus dos protocolos facultativos relativos a la abolición de la pena de muerte y a los derechos económicos, sociales y culturales, la Convención Interamericana sobre Desaparición Forzada de Personas y la Convención Interamericana para la eliminación de todas las formas de discriminación contra las personas con discapacidad

La ratificación de estos tratados internacionales por parte del estado de Honduras, tiene dos implicaciones importantes; en primer lugar el Estado se obliga a respetar y garantizar los derechos reconocidos en ellos y a adoptar las medidas legislativas o de otro carácter que fueren necesarias para hacerlos efectivos, respetarlos y garantizarlos sin discriminación alguna, garantizar el derecho a la garantías judiciales, el derecho a la igualdad ante la ley y el derecho a la protección judicial y cumplir las obligaciones que surgen de las normas sobre

25- Mejía R. Joaquín. Los Derechos Humanos en las sentencias de la Corte Interamericana sobre Honduras. Editorial Casa San Ignacio, Tegucigalpa. 2013 p. 100 . 
suspensión de garantías, interpretación y aplicación, y sobre correlación entre deberes y derechos.

En segundo lugar, al aceptar la competencia de los órganos encargados de supervisar la aplicación de tales instrumentos, les cede la potestad "para vigilar el cumplimiento de las obligaciones asumidas, determinar la extensión de los compromisos contraídos, interpretar el alcance de las disposiciones convencionales, evaluar la licitud de las reservas formuladas y, por supuesto, definir el alcance de su propia competencia"26.

En cuanto a la normativa hondureña que reconoce el derecho a un recurso rápido y sencillo contra actos u omisiones que transgredan los derechos humanos, tenemos: los tratados internacionales de derechos humanos, la Constitución de la República y las leyes secundarias, con especial énfasis la Ley de Justicia Constitucional.

Y como órgano garante de asegurar el respeto a las garantías judiciales y dar cumplimiento al derecho de la protección judicial en cualquier procedimiento en el que se determine el alcance de derechos humanos, está el Poder Judicial, en el cual los tribunales nacionales desempeñan un papel esencial en la aplicación de las disposiciones de los tratados internacionales de derechos humanos, teniendo el deber de verificar la conformidad de los actos y resoluciones emanadas de tales instrumentos.

Por lo tanto el Poder Judicial es un actor importante en la aplicación de las normas internacionales de derechos humanos, por tener la obligación de ejercer el control de convencionalidad entre las normas jurídicas internas que aplican en los casos concretos y las normas internacionales, en la que no solo se reconoce el principio de primacía constitucional y convencional, sino también la necesaria interacción entre el derecho internacional de derechos humanos y el derecho interno ${ }^{27}$.

Es así como los Jueces y Juezas, en virtud del principio del imperio de la ley y de los tratados internacionales de derechos humanos, están obligados a aplicar las disposiciones nacionales e internacionales vigentes en el ordenamiento jurídico, y cuando un Estado ratifica un tratado internacional, los funcionarios judiciales también están sometidos a él, lo que les obliga a ejercer una especie de control de convencionalidad.

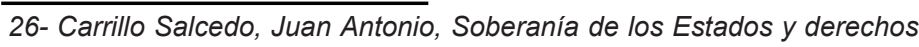
Humanos.......op.cit, p.109.

27- Mejía R. Joaquín. Los Derechos Humanos en las sentencias de la Corte Interamericana sobre Honduras. Editorial Casa San Ignacio, Tegucigalpa. 2013 p.108.
Finalmente es importante resaltar que la existencia de un Poder judicial competente, independiente e imparcial es uno de los elementos fundamentales para el debido control de constitucionalidad y convencionalidad, y en consecuencia, para el fortalecimiento de la democracia y del Estado de Derecho, pues constituye un derecho absoluto que no puede ser objeto de excepción alguna ${ }^{28}$.

\section{Conclusiones}

Conforme a lo expuesto en líneas precedentes se desprende y es oportuno concluir que el estado de Honduras, solo ha ejercido la función jurisdiccional ante la Corte Interamericana de Derechos Humanos, incurriendo de manera reiterada, en nuevos casos de responsabilidad internacional, al violentar los derechos consagrados en la Convención Americana de Derechos Humanos.

La función consultiva de la Corte Interamericana, a la fecha no ha sido utilizada por el estado de Honduras, por lo cual se recomienda a los Jueces que ante dudas e incertidumbre en la aplicación de tratados internacionales de derechos humanos a casos concretos en las que existan evidente violaciones a los derechos humanos, sometan a consulta estos tipos de casos, para evitar a posteriori la deducción de la responsabilidad internacional del Estado.

En materia de reparaciones ordenadas al estado de Honduras, por la Corte Interamericana, si bien existe una amplia y progresiva evolución de las medidas, por parte de este Tribunal a través de los años, el estado de Honduras ha sido deficiente en darle cumplimiento a las mismas, ya que actualmente se encuentran pendientes de cumplimiento y en etapa de supervisión, siete de las nueve sentencias en las cuales se ha declarado la responsabilidad internacional del Estado.

En cuanto al control de convencionalidad, el estado de Honduras reconoce el principio de primacía constitucional y convencional, así como la interacción entre el derecho internacional de los derechos humanos y el derecho interno, situación que obliga a los Jueces/zas a aplicar disposiciones nacionales e internacionales vigentes en el ordenamiento jurídico, dentro de un sistema de justicia independiente, imparcial y efectivo.

28- Corte IDH .Caso Ivcher Broinster Vs. Perú. Sentencia del 24 de septiembre de 1999. Párr. 112; Comité de Derechos Humanos, Caso González del Rio Vs. Perú. 28 de Octubre de 1992, Párr.5.2 


\section{Bibliografía}

\section{Libros}

- Mejía R. Joaquín. Los Derechos Humanos en las sentencias de la Corte Interamericana sobre Honduras. Editorial Casa San Ignacio, Tegucigalpa. 2013 p.108.

- Carrillo Salcedo, Juan Antonio, Soberanía de los Estados y derechos Humanos. op.cit, p.109.

\section{Sentencias Corte Interamericana de Derechos Humanos}

- CortelDH. Caso Velásquez Rodríguez Vs. Honduras. Fondo. Sentencia de 29 de julio de 1988.

- CortelDH. Caso Fairén Garbi y Solís Corrales Vs. Honduras. Fondo. Sentencia de 15 de marzo de 1989.

- CortelDH. Caso Godínez Cruz Vs. Honduras. Reparaciones y Costas. Sentencia de 21 de Julio de 1989.

- Corte IDH. Caso Juan Humberto Sánchez Vs. Honduras. Fondo. Sentencia 07 de Junio de 2003.

- Corte IDH. Caso López Álvarez. Fondo. Sentencia 01 de Febrero de 2006

- Corte IDH. Caso Servellón García y otros Vs. Honduras. Fondo, Reparaciones y Costas. Sentencia 21 de septiembre de 2006.

- Corte IDH. Caso Kawas Fernández Vs. Honduras. Fondo, Reparaciones y Costas. Sentencia 03 de Abril de 2009.

- $\quad$ Corte IDH. Caso Pacheco Teruel y otros Vs .Honduras. Fondo, Reparaciones y costas. Sentencia de 27 de abril de 2012.

- Corte IDH .Caso Luna López vs. Honduras. Fondo, Reparaciones y Costas. Sentencia de 10 de octubre de 2013.

- Corte IDH. Caso Lopez Lone y otros. Fondo. Sentencia de 05 de Octubre de 2015.

\section{Sitios Oficiales de Internet}

- Corte IDH: http://www.corteidh.or.crl 